\title{
Studies on the Combined Impact of Starch Source and Multiple Processing on Selected Properties of Thermoplastic Starch/Ethylene- Vinyl Acetate Blends
}

\author{
Aleksander Hejna $^{1,2} \cdot$ Joanna Lenża $^{1} \cdot$ Krzysztof Formela $^{2} \cdot$ Jerzy Korol $^{1}$
}

Published online: 5 March 2019

(c) The Author(s) 2019

\begin{abstract}
Thermoplastic starch (TPS)/ethylene vinyl acetate (EVA) blends compatibilized with polyethylene-graft-maleic anhydride (PE-g-MA) were prepared from various native starches (potato, maize and waxy maize) and subjected to multiple extrusion cycles. Source of starch has significant impact on its composition, hence properties of obtained TPS and their blends with EVA. Higher content of amylopectin in waxy maize starch, comparing to other types, enhanced the mechanical performance and increased tensile strength and elastic modulus even by 41 and $71 \%$, respectively. Such effect was related to the branching of amylopectin and was confirmed by SEM analysis of fracture areas, which showed more ductile behavior for blends with higher content of amylose. Multiple processing had beneficial impact on the performance of blends, due to the increasing compatibility and more homogenous structure after additional processing time. FTIR analysis indicated higher extent of compatibilization reaction, which, together with finer morphology, resulted in the enhancement of mechanical performance. Such effect is very beneficial from application point of view, because materials can be reprocessed without the loss of properties.
\end{abstract}

Keywords Recycling $\cdot$ Thermoplastic starch $\cdot$ Ethylene vinyl acetate $\cdot$ Sewage sludge $\cdot$ Multiple processing

\section{Introduction}

Application of starch in polymer industry is constantly gaining more attention due to its biodegradability and relatively low price, which fits into ongoing trends related to environmentally-friendly materials, often created by various law regulations. In order to improve starch processing and provide potential applications, it can be transformed into thermoplastic starch (TPS). Such process implicates the structural changes in starch, especially related to its crystallinity. In general, starch can be considered as a semicrystalline material. Nevertheless, when mixed with plasticizer and subjected to heat and shear, it loses its crystalline structure and becomes amorphous [1]. The most popular plasticizers of starch are water and glycerol, however researchers are

Jerzy Korol

jkorol@gig.eu

1 Department of Material Engineering, Central Mining Institute, Pl. Gwarków 1, 40-166 Katowice, Poland

2 Department of Polymer Technology, Gdansk University of Technology, Narutowicza 11/12, 80-233 Gdansk, Poland looking for other alternative compounds, which may provide the same or even superior properties of resulting TPS. The most popular compounds in the literature are, among others, sucrose, glucose, glycols, urea, amides and amino acids [2]. Thermoplastification of starch helps to overcome its biggest disadvantage - lack of thermoplastic character, and as a result, TPS can be processed with the most popular apparatus used in polymer technology, e.g. extruders and injection molding machines. Thermoplastification of starch has been comprehensively reviewed in previous works [3, 4]. However, TPS still has its drawbacks, which can be limited or eliminated by its application as component in polymer blends or composites. Such solutions may solve the processing problems, but also result in the enhancement of mechanical or thermal performance of material.

Over the last years, blending of TPS with various polymers became very popular topic among researchers all over the world. Many works describing the investigation of blends of TPS with polyethylene [5], natural rubber [6], poly(lactic acid) [7], poly(hydroxyalkanoates) [8], poly(acrylic acid) [9], poly(vinyl alcohol) [10] and others [11] have been published. However, researchers are still seeking for other opportunities to use starch in polymer blends. Very few 
works have been published regarding thermoplastic starch/ ethylene vinyl acetate (EVA) blends, despite the positive results [12]. Da Roz et al. [13] investigated the structure and properties of TPS blended with unmodified EVA and modified by hydrolysis of 50 or $100 \%$ of the vinyl acetate groups. Such modifications were motivated by the unsatisfactory compatibility of prepared blends. Generally, applied treatment of EVA resulted in the noticeable enhancement of blends' mechanical performance, as well as improvement of their thermal stability. Presented results encourage to further investigate structure and performance of TPS/EVA blends and their compatibilization by modification of one or two phases or incorporation of additional compatibilizer. Such modifications of TPS/EVA blends have not been previously reported in the literature.

Very important aspect of starch and starch-based materials, e.g. TPS/polymer blends, is its the type and structure, related to the content of amylose and amylopectin, two types of polysaccharides forming starch. Depending on the source of starch and its processing, it can contain these two components in very different ratio, which has significant impact on its structure and properties [14]. In many works, researchers investigated various sources of starch for manufacturing of TPS, such as potatoes, corn, rice, wheat, cassava, barley, pea or tapioca [4]. Although dependences between starch type and TPS properties were comprehensively analyzed in many works for native and thermoplastic starches, their influence on the structure and performance of TPS/polymer blends was described in only few works and mainly focused on TPS/PE and TPS/PP blends [15-17]. Therefore, with growing interest in new TPS/polymer blends, it is important to thoroughly investigate the compatibility, structure and performance of blends comprising of starches from different sources and with different content of amylose and amylopectin.

Above mentioned trends related to the environmentallyfriendly materials, as well as various law regulations are also indicating other direction of research regarding polymeric materials - their recycling. It is very important to remember, that the biggest advantage of polymer blends-possibility of combining the properties of different polymers, can be also a drawback, because of more complicated recycling procedures [18]. When blending two or more polymers with different structure and thermal properties, it is possible that processing conditions optimal for one of them may be unfavorable for another. Moreover, one of the polymers may be more sensitive to multiple processing and structural changes or even degradation may occur. Therefore, it is very important for potential industrial applications to determine the influence of multiple processing cycles on the performance of materials. Such investigations may result in the simultaneous development of recycling procedure, which is in line with currently promoted environmentally-friendly approaches. Up to that point, very few works associated with the multiple processing of polymer blends have been published in literature.

Presented research work had following goals: (i) to analyze the effectiveness of native starch thermoplastification with glycerol and sewage sludge instead of water, which could provide the method of its utilization; (ii) to evaluate the possibility of preparation of TPS/EVA blends with different types of starch, differing by amylose and amylopectin content, containing polyethylene-graft-maleic anhydride (PE-g-MA) as compatibilizer; (iii) to determine the impact of multiple extrusion cycles on the structure and properties of prepared TPS/EVA blends. These goals should be considered pro-ecological and environmentally-friendly, due to the use of biodegradable polymer-starch, application of waste material-sewage sludge, and investigation related to recycling of prepared materials. Above mentioned goals of presented work are accounting for the novelty of this paper. Application of sewage sludge as a plasticizer for starch is new trend and should result in the development of utilization method for this waste. Compatibilization of TPS/EVA blends has not been previously reported, the same for the impact of starch type, as well as the multiple processing cycles on the structure and performance of these blends.

\section{Experimental}

\section{Materials}

First step of was thermoplastification of native starches. Three types of starch were applied in presented research: potato starch (SZ), maize starch (SK) and waxy maize starch (SKW). Characteristics of applied polysaccharides are presented in Table 1.

For thermoplastification previously prepared mixture of glycerol and sewage sludge was used. Glycerol with purity of 99.5\% was obtained from Avantor Performance Materials Poland. Sewage sludge was recieved from Gigablok sewage treatment plant, which belongs to Katowicka Infrastruktura Wodociągowo-Kanalizacyjna Sp. z o.o., while object is operated by Spółka Katowickie Wodociaggi S.A. Characteristics of used sewage sludge is presented in Table 2.

Obtained thermoplastic starches were reactively extruded with ethylene-vinyl acetate copolymer (EVA)—Exan Mobil Escorene Ultra EVA Copolymer FL00218, with vinyl acetate content of $18 \mathrm{wt} \%$, and compatibilizer-polyethylene-graftmaleic anhydride (PE-g-MA), with maleic anhydride content of $1.7 \mathrm{wt} \%$ and trade name Polybond Clariant Licocene PEMA 4351 GRTP. PE-g-MA was selected as a compatibilizer for prepared materials, due to the good miscibility with EVA and ability to create covalent bonds with hydroxyl 
Table 1 Characteristics of applied starches

\begin{tabular}{llll}
\hline Symbol & SZ & SK & SKW \\
\hline Type & Potato & Maize & Waxy maize \\
Amylose content, wt $\%$ & 30 & 26 & 1 \\
Amylopectin content, wt $\%$ & 70 & 74 & 99 \\
Moisture content, wt $\%$ & 12 & 10 & 8 \\
Gelatinization temperature, ${ }^{\circ} \mathrm{C}$ & 95.4 & 92.5 & 88.5 \\
Producer & Nowamyl & Cargill & Cargill \\
Trade name & Super standard & C Gel 03401 & C Gel 04201
\end{tabular}

Table 2 Characteristics of sewage sludge

\begin{tabular}{|c|c|c|}
\hline Component & & Content, wt $\%$ \\
\hline Moisture & & 80.64 \\
\hline Dry mass & & 19.36 \\
\hline Component & \multicolumn{2}{|c|}{ Content, wt $\%$ of dry mass } \\
\hline Organic compounds & 64.61 & \\
\hline Volatiles & 54.96 & \\
\hline Ash & 35.39 & \\
\hline $\mathrm{C}$ & 34.52 & \\
\hline $\mathrm{H}$ & 4.98 & \\
\hline $\mathrm{N}$ & 8.80 & \\
\hline $\mathrm{O}$ & 15.16 & \\
\hline $\mathrm{S}$, total & 1.20 & \\
\hline $\mathrm{S}$, ash & 0.05 & \\
\hline S, combustible & 1.15 & \\
\hline $\mathrm{P}$ & 3.68 & \\
\hline K & 0.50 & \\
\hline $\mathrm{Mg}$ & 0.92 & \\
\hline $\mathrm{Ca}$ & 2.34 & \\
\hline $\mathrm{Fe}$ & 5.23 & \\
\hline Property & & Value, $\mathrm{kJ} / \mathrm{kg}$ \\
\hline Heat of combustion & & 13,410 \\
\hline Heating value-as recieved & & 780 \\
\hline Heating value-dry material & & 14,230 \\
\hline
\end{tabular}

groups present in the structure of starch. General scheme of this reaction is presented in Fig. 1.

\section{Starch Modification}

Basing on literature data, $25 \mathrm{wt} \%$ addition of glycerol was used for starch thermoplastification [19]. Sewage sludge was also added to the starch as plasticizer in the amount of $31.25 \mathrm{wt} \%$, in order to equal the amount of water and glycerol (water content of sewage sludge was $80 \mathrm{wt} \%$ ). Applied native starches were not dried before thermoplastification, because water is facilitating the whole process, so drying was unnecessary.

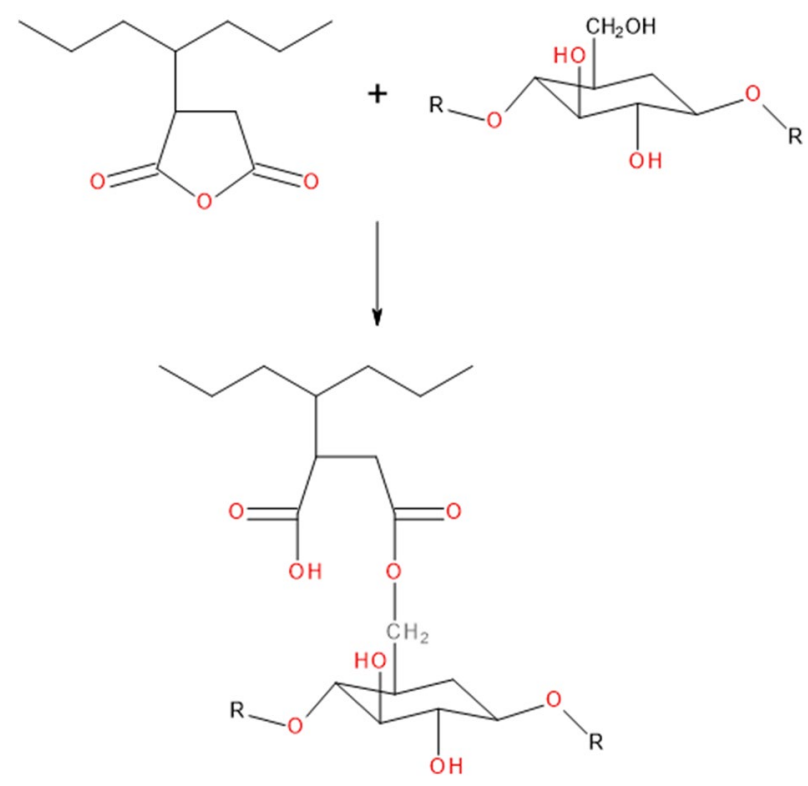

Fig. 1 Scheme of reaction between TPS and PE-g-MA

Next, important step of starch preparation before extrusion was granulation, which was performed in Intensive Mixer Eirich R02 manufactured by Maschinenfabrik Gustav Eirich (Germany). Such procedure is innovative method for preparation of powders for further processing, e.g. extrusion. Comparing to powders, when materials are in form of granules, their metering to extruder is more controlled. During the process, native starch was also pre-mixed with glycerol and sewage sludge, so thermoplastification was initiated. Mixing parameters: agitator rotations $3000 \mathrm{rpm}$, pan rotations $120 \mathrm{rpm}$, mixing time $60 \mathrm{~s}$. Granulation parameters: first stage of granulation-to build granules: agitator rotations $2100 \mathrm{rpm}$, pan rotations $120 \mathrm{rpm}$ for $180 \mathrm{~s}$, second stage of granulation - to make granules smooth: agitator rotations $900 \mathrm{rpm}$, pan rotations $120 \mathrm{rpm}$ for $60 \mathrm{~s}$.

In order to prepare thermoplastic starch, granules were extruded with the use of enhanced technological installation based on the $(\mathrm{L} / \mathrm{D}=28)$ Leistritz ZSE model $27 \mathrm{HP}$ twin screw extruder equipped with a die with three orifices of 
circle diameter of $3 \mathrm{~mm}$, BRABENDER gravimetric screw feeders ensuring proportion accuracy of 0.1 by wt $\%$, as well as CF SCHEER and CIE SGS 50E granulator. In Table 3 there are presented process parameters. Temperature profile of extruder was adjusted on the basis of our previous work [20]. Slight changes were related to the different composition of thermoplastic starch than in cited work.

\section{TPS/EVA Blends Preparation}

TPS/EVA blends were prepared via reactive extrusion. In order to enhance the interfacial adhesion, PE-g-MA was applied as compatibilizer. Its content was constant and equaled $5 \mathrm{wt} \%$. Content of TPS was also constant- $65 \mathrm{wt} \%$, which resulted in the fact that TPS accounted for continuous phase in prepared blends, making them susceptible to biodegradation. Each blend was extruded three times, in order to determine the impact of multiple extrusion cycles on their structure and properties.

All blends were prepared using a twin screw extruder Leistritz ZSE model 27 HP (Germany). The screw diameter was $27 \mathrm{~mm}$, and a length to diameter ratio was 44 $(\mathrm{L} / \mathrm{D}=44)$. Constructions of used plasticizing systems and detailed description of screws are shown in details in previous works [21, 22]. The extruder had 10 heating and cooling zones. All materials were dosed by Brabender gravimetric screw feeders (Germany) with a constant flow rate. In Table 4 there are shown parameters of all three extrusion cycles. Temperature profile of extruder was adjusted on the basis of previous works associated with the TPS/EVA blends $[12,13]$. However, temperatures were increased, due to the incorporation of PE-g-MA compatibilizer, in order to lower the viscosity of the system and provide the best conditions for efficient mixing. In the following extrusion cycles, temperatures of extrusion were lowered due to easier processing in order to maintain efficient level of motor load. Moreover, in the Fig. 2, there are presented images of extruded blends before and after granulation. It can be seen that granules of prepared blends show porous structure, which is associated with the moisture content of applied native starches and the addition of water, which acted as plasticizer during conversion of native starches into thermoplastic starches.
Obtained blends were injection molded using Arburg type Allrounder 270-210-500 injection-molding machine into standard so called dog-bone specimens (ASTM 527) with the cross section of the measurement part equal 40 $\mathrm{mm}^{2}$. The machine is equipped with Priamus (Switzerland) injection process controller. ARBURG Allrounder characteristics: screw diameter: $25 \mathrm{~mm}$, injection pressure-max $1400 \mathrm{bar}$, clamping force-500 kN. Sample injection parameters: temperature of the polymer melt $-120{ }^{\circ} \mathrm{C} \pm 2{ }^{\circ} \mathrm{C}$, form temperature $-20{ }^{\circ} \mathrm{C} \pm 1{ }^{\circ} \mathrm{C}$, injection speed $-190 \mathrm{~mm} / \mathrm{s}$, cycle period- $60 \mathrm{~s}$, injection pressure $-650 \mathrm{bar}$, clamping pressure-350 bar.

Samples after injection molding were coded as KXY, where $\mathrm{X}$ stands for type of native starch and $\mathrm{Y}$ for the numer of extrusion cycle, hence TPS/EVA blend based on maize starch after second extrusion cycle is named KSK2.

\section{Measurements}

Chemical structure of used materials, as well as prepared blends was determined using Fourier transform infrared spectroscopy (FTIR) analysis performed by a Nicolet Spectrometer IR200 from Thermo Scientific (USA). The device had ATR attachment with a diamond crystal. Measurements were performed with $1 \mathrm{~cm}^{-1}$ resolution in the range from 4000 to $400 \mathrm{~cm}^{-1}$.

The tensile strength, elongation at break and elastic modulus were estimated in accordance with PN-EN ISO 527 standard, using the Instron 4465H 1937 tensile testing machine with elongation head and extensometer. Tensile tests were performed at a constant speed of $1 \mathrm{~mm} / \mathrm{min}$ (for elastic modulus) and $50 \mathrm{~mm} / \mathrm{min}$ (tensile strength and elongation at break). Five samples were analyzed for each specimen.

Thermal characteristics of the blends were determined using a differential scanning calorimeter Mettler-Toledo TGA/DSC 1 (Switzerland). Programme 2H2C 30/180/10/ $\mathrm{N} 2 / 40 \mu \mathrm{l}$ was applied during analysis, which consisted of two heating and two cooling cycles, from 30 to $180{ }^{\circ} \mathrm{C}$ with the heating rate of $10{ }^{\circ} \mathrm{C} / \mathrm{min}$. Analysis was performed in nitrogen atmosphere.

The morphology of the samples and the fracture surfaces created by breaking the samples during the tensile
Table 3 Parameters of starch extrusion process

\begin{tabular}{|c|c|c|c|c|c|c|c|c|c|c|c|}
\hline \multirow[t]{2}{*}{ Type of starch } & \multicolumn{8}{|c|}{ Temperature at particular sections, ${ }^{\circ} \mathrm{C}$} & \multirow[t]{2}{*}{$\mathrm{T}_{\mathrm{w},}{ }^{\circ} \mathrm{C}$} & \multirow[t]{2}{*}{ P, bar } & \multirow[t]{2}{*}{$\mathrm{W}, \mathrm{kg} / \mathrm{h}$} \\
\hline & S1 & S2 & S3 & S4 & S5 & S6 & D1 & D2 & & & \\
\hline SZ & 60 & 80 & 90 & 110 & 120 & 130 & 125 & 120 & 141 & 5 & 18 \\
\hline SK & 60 & 80 & 90 & 110 & 120 & 130 & 125 & 120 & 143 & 7 & 20 \\
\hline SKW & 60 & 80 & 90 & 110 & 120 & 130 & 125 & 120 & 139 & 8 & 22 \\
\hline
\end{tabular}

where S1-S6 — heated zones, D1-pressure measurement ring, D2-head, $\mathrm{T}_{\mathrm{w}}$ - starch temperature, $\mathrm{P}$ starch pressure, $\mathrm{W}-$ yield 
Table 4 Parameters of three extrusion cycles of prepared blends

\begin{tabular}{|c|c|c|c|c|c|c|c|c|c|c|}
\hline \multirow[t]{2}{*}{ Type of starch } & \multicolumn{7}{|c|}{ Temperature at particular sections, ${ }^{\circ} \mathrm{C}$} & \multirow[t]{2}{*}{$\mathrm{T}_{\mathrm{w}},{ }^{\circ} \mathrm{C}$} & \multirow[t]{2}{*}{ P, bar } & \multirow[t]{2}{*}{$\mathrm{W}, \mathrm{kg} / \mathrm{h}$} \\
\hline & S1 & S2 & S3 & S4-S8 & S9 & S10 & D1-D2 & & & \\
\hline \multicolumn{11}{|c|}{ First extrusion cycle } \\
\hline SZ & 80 & 100 & 120 & 130 & 140 & 140 & 140 & 144 & 21 & 10 \\
\hline SK & 80 & 100 & 120 & 130 & 140 & 140 & 140 & 148 & 27 & 10 \\
\hline SKW & 80 & 100 & 120 & 130 & 140 & 140 & 140 & 146 & 22 & 10 \\
\hline \multicolumn{11}{|c|}{ Second extrusion cycle } \\
\hline SZ & 75 & 95 & 115 & 120 & 120 & 130 & 130 & 135 & 42 & 10 \\
\hline SK & 75 & 95 & 115 & 120 & 120 & 130 & 130 & 137 & 37 & 10 \\
\hline SKW & 75 & 95 & 115 & 120 & 120 & 130 & 130 & 136 & 32 & 10 \\
\hline \multicolumn{11}{|c|}{ Third extrusion cycle } \\
\hline SZ & 65 & 90 & 105 & 105 & 105 & 110 & 110 & 110 & 54 & 10 \\
\hline SK & 65 & 90 & 105 & 105 & 105 & 110 & 110 & 112 & 60 & 10 \\
\hline SKW & 65 & 90 & 105 & 105 & 105 & 110 & 110 & 112 & 54 & 10 \\
\hline
\end{tabular}

where S1-S10-heated zones, D1-pressure measurement ring, D2-head, $\mathrm{T}_{\mathrm{w}}$ - starch temperature, Cstarch pressure, $\mathrm{W}-$ yield test at the speed of $50 \mathrm{~mm} / \mathrm{min}$ was evaluated by using a HITACHI model S-3400N scanning electron microscope equipped with EDS Thermo NORAN System Six and EBSD detector INCA HKL Nordlys II. Detailed chemical composition measurements of the samples' cross-sections were performed using the EDS technique. Samples were not sputtered, acceleration of $15 \mathrm{kV}$ was used.

\section{Results and Discussion}

\section{Analysis of Native Starches and Sewage Sludge}

In the Figs. 3 and 4 there are shown FTIR spectra of applied native starches. Spectra are typical for polysaccharide-based materials. In the Fig. 3 there is shown basic comparison of spectra, while in the Fig. 4 signals that differ between various types of starches are shown in more details. Peaks (a) at $3266 \mathrm{~cm}^{-1}$ are characteristic for stretching vibrations of hydroxyl groups, which are responsible for the reaction with maleic anhydride. Signals (b) in the range of 2880-2930 $\mathrm{cm}^{-1}$ are associated with the symmetric and asymmetric stretching of $\mathrm{C}-\mathrm{H}$ bonds in methylene groups, while bending and deformation vibrations of these groups are represented by the peaks (f and i) at 1076 and $860 \mathrm{~cm}^{-1}$, respectively. The highest intensity of these signals is observed for waxy maize starch, which is related to the highest content of amylopectin (see Fig. 4) [23]. Band (c) observed at $1634 \mathrm{~cm}^{-1}$ is associated with the water absorbed in the amorphous region of starch [24]. Multiple peaks (d) noted in the range of $1240-1460 \mathrm{~cm}^{-1}$ are characteristic for bending and deformation vibrations of $\mathrm{C}-\mathrm{H}$ bonds, as well as bending of C-O-H [25]. Signal (e) at $1148 \mathrm{~cm}^{-1}$ is related to the stretching of $\mathrm{C}-\mathrm{O}$ bonds, present in the structure of starch. Around $993 \mathrm{~cm}^{-1}$ can be observed intense band $(\mathrm{g})$, whose structure is depending on crystallinity and moisture content of analyzed starch [26]. In general, this band consists of few overlapping bands (typically around 1022 and $1047 \mathrm{~cm}^{-1}$ ), whose intensity may be used to estimate the content of ordered and amorphous phase in starch [27]. Intensity of signals at 993 and $1047 \mathrm{~cm}^{-1}$ increase with increasing crystallinity, hence amylopectin content. In the Fig. 4 it can be clearly seen that magnitude of these signals is $\sim 20-30 \%$ higher for waxy maize starch comparing to potato starch, which is in line with the characteristics of applied starches [28]. Also, it is worth to mention that separation of these bands become more evident for higher water content, exceeding $20 \mathrm{wt} \%$ [26]. Peak (h) at $927 \mathrm{~cm}^{-1}$ can be associated with skeletal vibrations of $\alpha-1,4$-glycosidic linkages between glucose particles. Below $800 \mathrm{~cm}^{-1}$ spectra exhibit very complex structure, which is related to the multiplicity of skeletal vibrations of glucose pyranose rings [29].

Moreover, in the Fig. 5 there is presented FTIR spectra of sewage sludge. The most intensive signal (a), observed at $3264 \mathrm{~cm}^{-1}$ is related to the high content of water in material and associated with the stretching vibrations of hydroxyl groups, as well as intermolecular hydrogen bonds. Band (b) at $1635 \mathrm{~cm}^{-1}$ is associated with the $\mathrm{O}-\mathrm{H}-\mathrm{O}$ scissors-bending [30]. Peak (c) at $1031 \mathrm{~cm}^{-1}$ can be attributed to the $\mathrm{Si}-\mathrm{O}$ stretching vibrations [31].

\section{Thermoplastification of Starches}

In the Fig. 6 there are presented DSC thermograms for applied starches before and after thermoplastification. On all of the curves of native starches, there are present peaks 

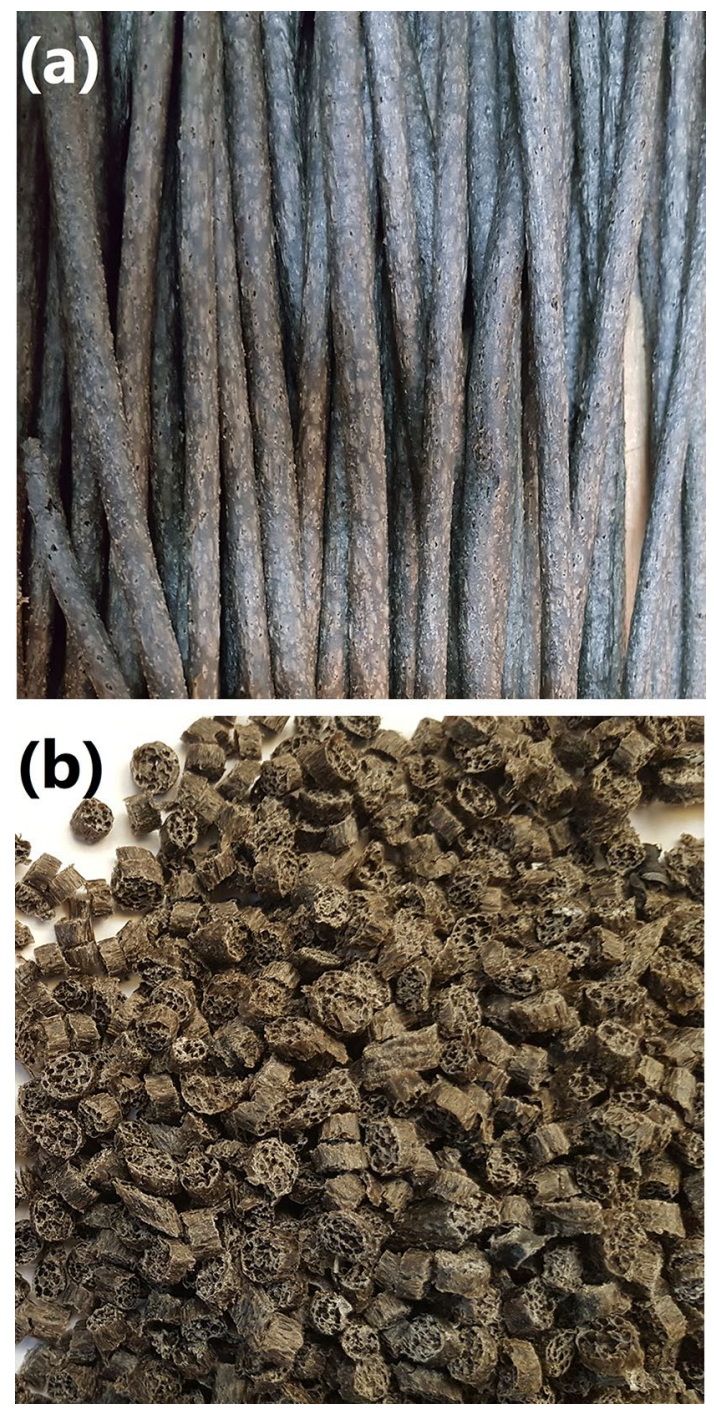

Fig. 2 Appearance of extruded blends $\mathbf{a}$ before and $\mathbf{b}$ after granulation

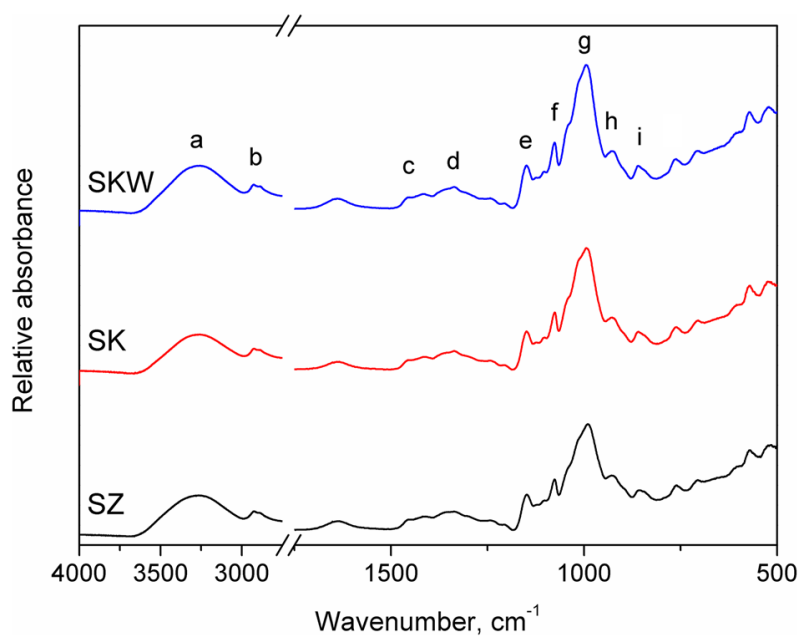

Fig. 3 Comparison of FTIR spectra of native starches

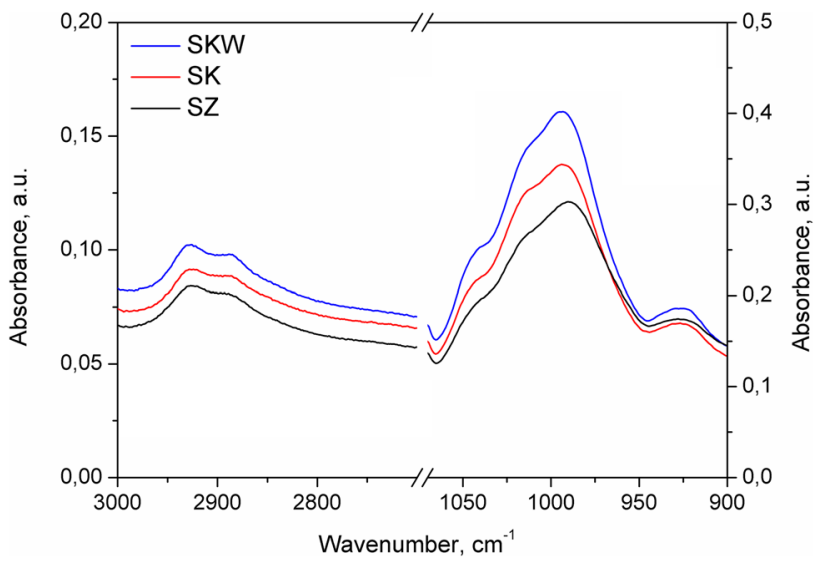

Fig. 4 Detailed FTIR spectra of native starches

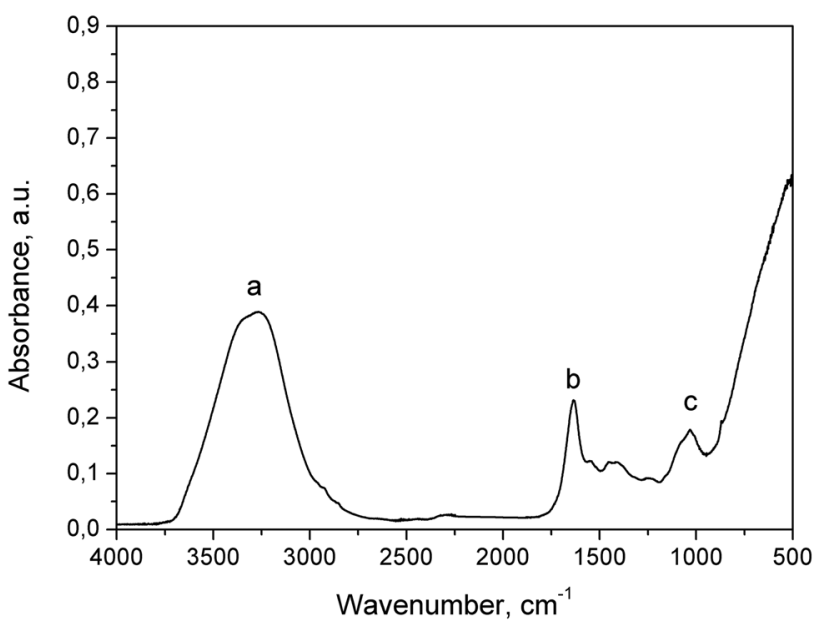

Fig. 5 FTIR spectra of used sewage sludge

characteristic for starch gelatinization [32]. It is a process related to the swelling of starch granules and reduction of their crystallinity due to the diffusion of crystalline regions in amylose and reduction of the size of crystalline regions. Temperatures of gelatinization of applied starches, determined by DSC analysis, are presented in Table 1. Differences in these temperatures and size of peaks shown in the Fig. 6, are directly associated with the structure of material and content of amylose and amylopectin. Peak temperature of gelatinization is correlated with the quality of crystallites, but enthaply of the process is associated with overall measure of crystallinity, both quality and quantity. Therefore, starches containing more amylopectin, require more energy to gelatinize, increasing the magnitude of the peaks, which can be seen in the Fig. 6 [33]. Moreover, enthalpy of the process is associated with the type of crystallinity in starch, maize starches show A-type of crystallinity, which increases enthalpy comparing to B-type starches, e.g. potato starch 
[34]. Type of starches crystallinity was later determined by XRD analysis. Therefore, determined gelatinization temperatures are in line with the presented characteristics of applied starches. Signals observed above $275^{\circ} \mathrm{C}$ are associated with thermal decomposition of starches [35].

Thermograms of starches obtained after thermoplastification did not show signals characteristic for melting, therefore it can be concluded that no crystalline structures are present in material, which confirms effective thermoplastification. Only small steps associated with the glass transition of starches are observed. Glass transition temperatures $\left(T_{g}\right)$ of investigated TPS samples are presented in the Fig. 6. It can be seen that $T_{g}$ value is associated with the type of starch, hence its composition. Increasing content of amylopectin resulted in the shift of $\mathrm{T}_{\mathrm{g}}$ towards higher temperatures, which confirms the results presented in other works [36].

Moreover, in the Fig. 7 there are shown XRD diffraction patterns of applied starches. Patterns of all unmodified samples clearly indicate the semicrystalline nature of starch, which is expressed by presence of multiple sharp
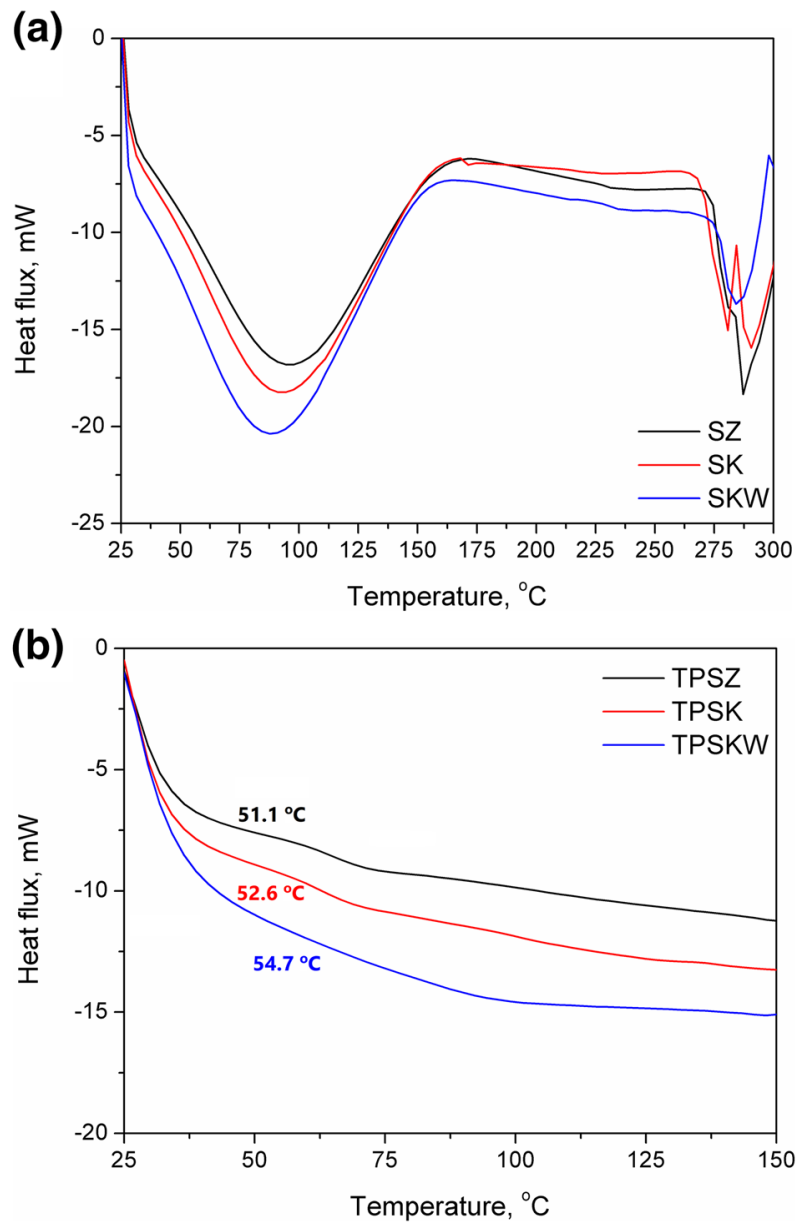

Fig. 6 DSC thermograms of $\mathbf{a}$ native starches and $\mathbf{b}$ thermoplastic starches peaks. It can be seen that potato starch show pattern characteristic for B-type of crystallinity, which is represented by dominating peak at $17.1^{\circ}$ [37]. B-type structures are not so closely packed and more open with water molecules located in the cavity between helical structures. Maize starch and especially waxy maize starch represent A-type crystallinity, which is represented by intense peaks at $15.3^{\circ}$ and $23.1^{\circ}$, not observed for potato starch. This type of structure shows higher packing level. In general, patterns obtained for all starches are very similar to those presented for the same types by other researchers $[38,39]$.

According to literature data, XRD patterns of starch after thermoplastification may still show peaks associated with crystalline structure, either residual crystallinity resulting from incomplete melting or processing-induced crystallinity type V [40]. Nevertheless, in presented case, no peaks are observed after thermoplastification, only one broad, fuzzy signal which is characteristic for amorphous materials [41]. Such effect is related to the effective disruption of starch structure by melting and granular swelling, and proves that thermoplastification was effective [42].

\section{FTIR Analysis of TPS/EVA Blends}

In the Fig. 8 there are shown FTIR spectra of TPS/EVA blends depending on the amount of extrusion cycles applied. Signals (a) at $3300-3314 \mathrm{~cm}^{-1}$ are associated with the stretching vibrations of hydroxyl groups present in the structure of starch and generated during reaction between starch and maleic anhydride grafted to polyethylene compatibilizer. Slight increase of this signal can be associated with the extent of this reaction. Moreover, position of this signal was shifted towards higher wavenumbers, which points to effective interactions between hydroxyl group of various phases [43]. Peaks (b) at 2847 and $2916 \mathrm{~cm}^{-1}$ related to the symmetric and asymmetric stretching of $\mathrm{C}-\mathrm{H}$ bonds were hardly affected by the multiple processing cycles, just as the ones (d) at 1369 and $1463 \mathrm{~cm}^{-1}$ attributed to the deformation vibrations of $\mathrm{C}-\mathrm{H}$ bonds. Only slight decrease of peaks' magnitude after third extrusion was noted, which may be related to partial decomposition of starch particles caused by temperature and shear forces acting on material during processing. Signal (c) observed at $1738 \mathrm{~cm}^{-1}$ was associated with the stretching vibrations of carbonyl groups present in the maleic anhydride and vinyl acetate and was hardly affected by the amount of processing cycles. Peaks (e and f) observed in the range of $928-1238 \mathrm{~cm}^{-1}$ were also sensitive for the amount of processing cycles. These peaks were attributed to the $\mathrm{C}-\mathrm{O}$ and $\mathrm{C}-\mathrm{O}-\mathrm{C}$ stretching and in this case, changes in their intensity are correlated with the extent of reaction between maleic anhydride and starch, which results in generation of ether bonds (see Fig. 1) [44]. Observed changes of spectra suggest higher completion of 


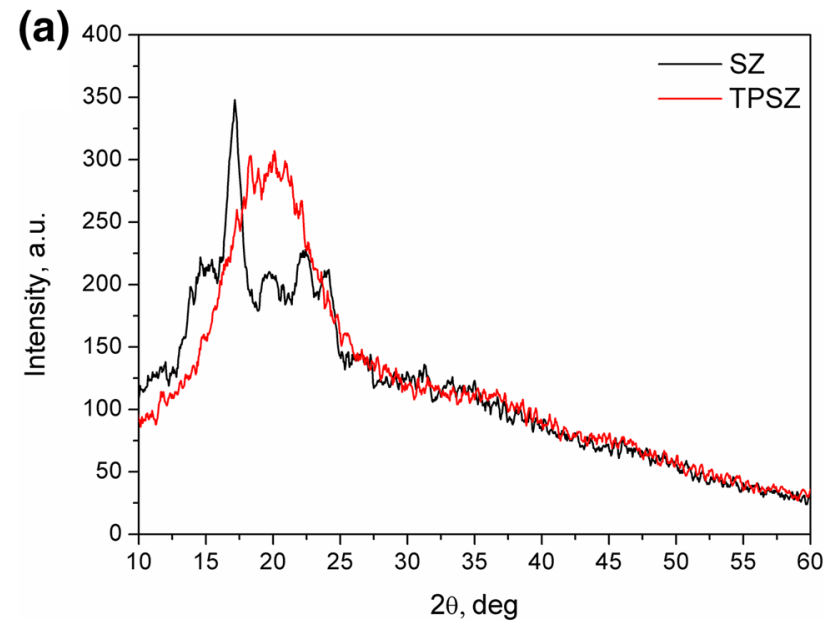

(b)
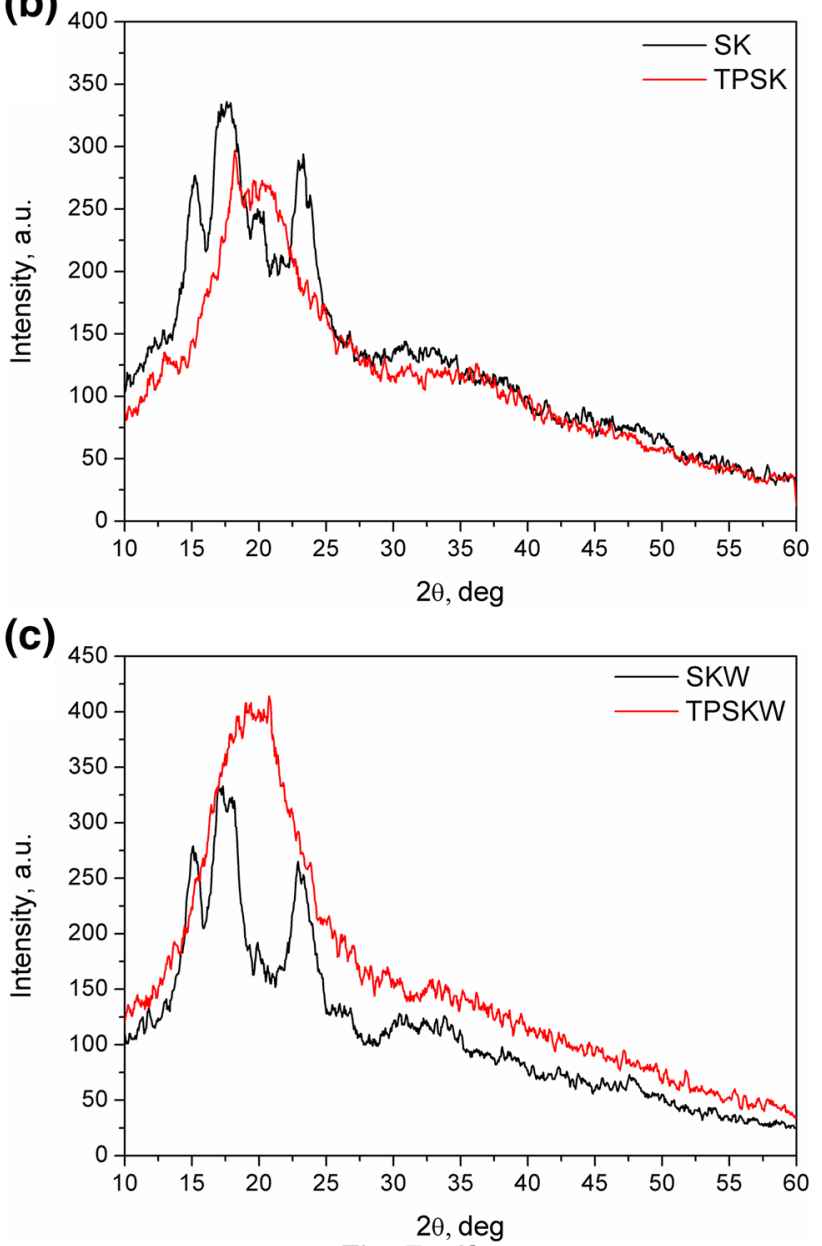

Fig. 7c.tif

Fig. 7 XRD spectra of a potato starch, b maize starch and $\mathbf{c}$ waxy maize starch, before and after thermoplastification

this reaction with elongation of processing time. Signals $(\mathrm{g})$ observed below $900 \mathrm{~cm}^{-1}$ are associated with the bending and deformation vibrations of $\mathrm{C}-\mathrm{H}$ and $\mathrm{C}-\mathrm{C}$ bonds present

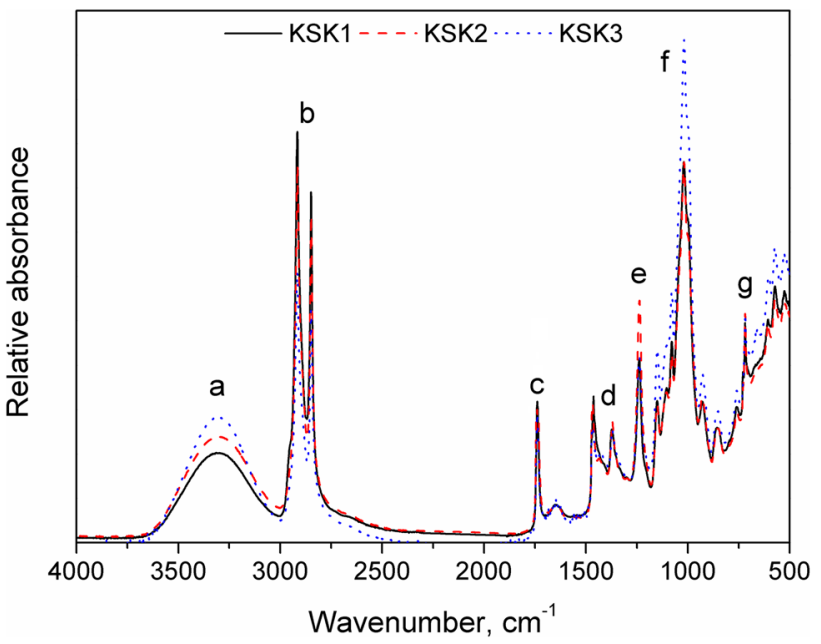

Fig. 8 FTIR spectra of TPS/EVA composites depending on amount of processing cycles

in the hydrocarbon chains of polyethylene, as well as in starch and vinyl acetate.

In the Fig. 9 there are show FTIR spectra of TPS/EVA blends containing different types of starch. Some differences in spectra can be observed. Influence of starch type on the intensity of signal associated with hydroxyl groups can be noted, but changes are not so strong as in case of multiple processing cycles. Peaks related to the symmetric and asymmetric stretching (3300-3314 $\left.\mathrm{cm}^{-1}\right)$, as well as deformation vibrations (1369 and $1463 \mathrm{~cm}^{-1}$ ) of $\mathrm{C}-\mathrm{H}$ bonds were slightly sensitive to starch type, which may be due to the difference in amylose and amylopectin content. However, the strongest impact of starch type was observed for signals associated with the stretching vibrations of $\mathrm{C}-\mathrm{O}$ and $\mathrm{C}-\mathrm{O}-\mathrm{C}$ bonds $\left(928-1238 \mathrm{~cm}^{-1}\right)$, which is related to the presence of $\alpha-1,6-$ glycosidic bonds responsible for branching in amylopectin structure [45]. Such results are in line with the FTIR analysis and presented characteristics of applied native starches.

\section{Mechanical Properties of TPS/EVA Blends}

In Table 5 there are presented static mechanical properties of prepared materials. It can be seen that for all analyzed composites, multiple processing cycles resulted in the enhancement of materials' stiffness and tensile strength. Such effect may be related to the better mixing of material, hence improved homogeneity of materials, which was later confirmed by SEM analysis [46]. Other factor influencing compatibility of material, so also its mechanical performance, may be reaction occurring between maleic anhydride grafted to PE compatibilizer and hydroxyl groups present in the structure of thermoplastic starch [20, 47]. Moreover, as a result of increased stiffness of material, elongation at break was noticeably decreased by multiple processing. 


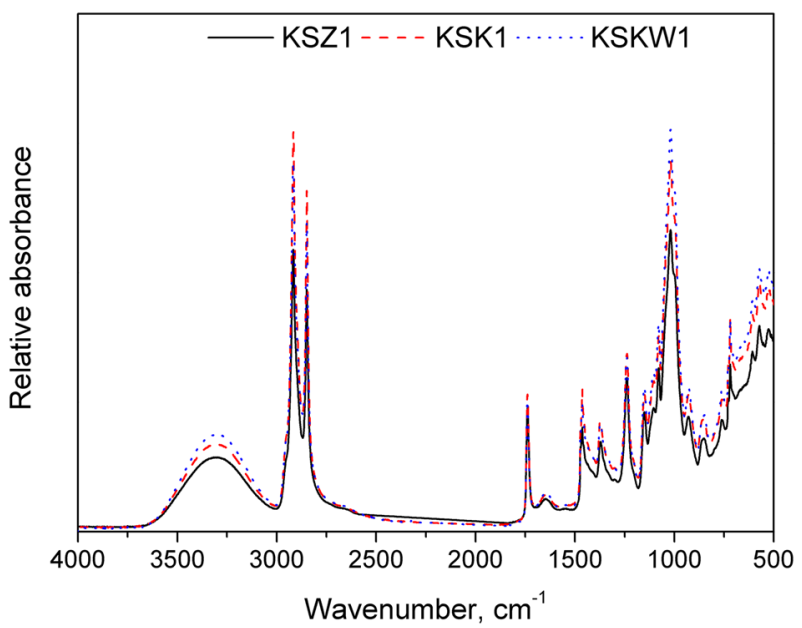

Fig. 9 FTIR spectra of TPS/EVA composites containing different types of starch

Differences in tensile properties between materials containing different types of starch are associated with the amylose and amylopectin content. With increasing content of amylopectin, tensile strength was increasing, which confirms the results presented by other authors [48].

The highest values of elongation at break were observed for samples containing potato starch, which contains the highest amount of amylose. Therefore, it contains less branched structures, which are restricting polymer chains' mobility. Such effect was confirmed by SEM analysis of samples after tensile tests. Samples with SZ show the most ductile behavior, while materials with SKW show even brittle break areas. Such effect related to starch composition was also observed in other works [49].

\section{Thermal Properties of TPS/EVA Blends}

In the Figs. 10 and 11, there are shown results of DSC analysis of prepared composites and their components.

Table 5 Tensile properties of analyzed TPS/EVA blends

\begin{tabular}{llcc}
\hline Sample & $\begin{array}{l}\text { Tensile } \\
\text { strength, MPa }\end{array}$ & Elastic modulus, MPa & $\begin{array}{l}\text { Elongation } \\
\text { at break, } \%\end{array}$ \\
\hline KSZ1 & $5.4 \pm 0.4$ & $47.9 \pm 0.6$ & $194 \pm 3$ \\
KSZ2 & $5.7 \pm 0.2$ & $52.1 \pm 1.4$ & $174 \pm 2$ \\
KSZ3 & $5.8 \pm 0.1$ & $74.6 \pm 2.8$ & $76 \pm 5$ \\
KSK1 & $4.7 \pm 0.1$ & $39.7 \pm 1.2$ & $120 \pm 7$ \\
KSK2 & $6.7 \pm 0.1$ & $91.8 \pm 7.4$ & $65 \pm 4$ \\
KSK3 & $7.1 \pm 0.1$ & $106.9 \pm 7.4$ & $67 \pm 7$ \\
KSKW1 & $5.6 \pm 0.1$ & $83.1 \pm 2.2$ & $66 \pm 9$ \\
KSKW2 & $6.0 \pm 0.0$ & $95.3 \pm 5.9$ & $65 \pm 2$ \\
KSKW3 & $8.2 \pm 0.4$ & $128.2 \pm 5.7$ & $25 \pm 3$ \\
\hline
\end{tabular}

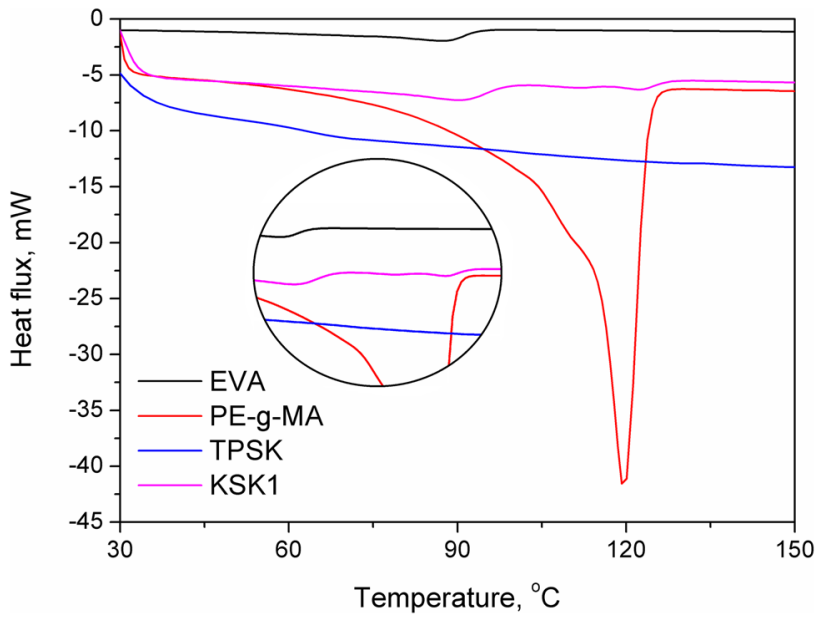

Fig. 10 Thermograms of used materials and resulting KSK1 TPS/ EVA blend

Thermograms for compounds used during preparation of composites and for KSK composite are shown in the Fig. 8, in order to clearly indicate the origin of each observed peak. It can be seen that in thermograms of analyzed composites are clearly represented signals characteristic for melting of EVA and PE-g-MA. Obviously, the intensity of these signals is lower for composite, due to smaller content of particular compounds (especially in the case of PE-g-MA). Moreover, in composite sample can be observed very small peak around $110^{\circ} \mathrm{C}$, which is related to the generation of crystalline structure during processing of TPS with other compounds [33].

In the Fig. 11 there are shown thermograms of composites based on maize starch prepared after 1,2 and 3 cycles of extrusion. All of them present very similar course, however

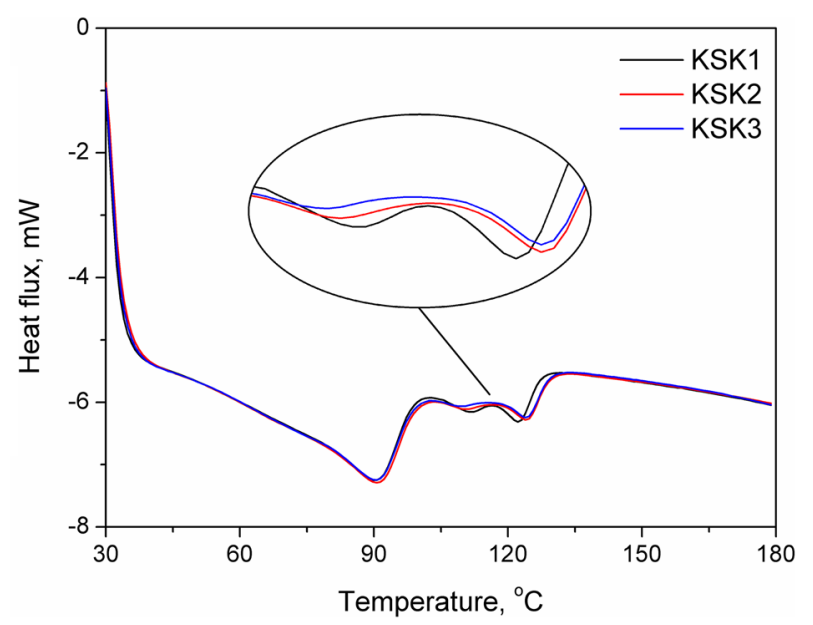

Fig. 11 Impact of multiple extrusion cycles on thermal properties of TPS/EVA blends 
Table 6 Melting characteristics and degree of crystallinity of used materials and TPS/EVA blends

\begin{tabular}{|c|c|c|c|c|c|c|c|c|c|c|}
\hline Sample & $\mathrm{T}_{\mathrm{m} 1},{ }^{\circ} \mathrm{C}$ & $\Delta \mathrm{H}_{\mathrm{m} 1}, \mathrm{~J} / \mathrm{g}$ & $\mathrm{W}_{\mathrm{m} 1 / 2-1},{ }^{\circ} \mathrm{C}$ & $\mathrm{T}_{\mathrm{m} 2},{ }^{\circ} \mathrm{C}$ & $\Delta \mathrm{H}_{\mathrm{m} 2}, \mathrm{~J} / \mathrm{g}$ & $\mathrm{W}_{\mathrm{m} 1 / 2-2},{ }^{\circ} \mathrm{C}$ & $\mathrm{T}_{\mathrm{m} 3},{ }^{\circ} \mathrm{C}$ & $\Delta \mathrm{H}_{\mathrm{m} 3}, \mathrm{~J} / \mathrm{g}$ & $\mathrm{W}_{\mathrm{m} 1 / 2-3},{ }^{\circ} \mathrm{C}$ & $X_{c}, \%$ \\
\hline TPSZ & - & - & - & - & - & - & - & - & - & - \\
\hline TPSK & - & - & - & - & - & - & - & - & - & - \\
\hline TPSKW & - & - & - & - & - & - & - & - & - & - \\
\hline EVA & 87.4 & 42.9 & 18.2 & - & - & - & - & - & - & 14.6 \\
\hline PE-g-MA & - & - & - & - & - & - & 119.5 & -178.4 & 6.7 & 60.9 \\
\hline KSZ1 & 89.6 & -16.6 & 25.0 & 110.3 & -0.34 & 6.1 & 122.2 & -1.3 & 5.2 & 17.5 \\
\hline KSZ2 & 88.9 & -16.1 & 25.2 & 109.1 & -0.24 & 5.7 & 122.4 & -1.2 & 5.3 & 16.9 \\
\hline KSZ3 & 88.8 & -16.1 & 26.0 & 107.9 & -0.19 & 5.3 & 122.8 & -1.2 & 5.3 & 16.7 \\
\hline KSK1 & 90.1 & -15.6 & 25.3 & 111.4 & -0.37 & 6.1 & 122.7 & -1.1 & 5.2 & 16.3 \\
\hline KSK2 & 90.4 & -15.3 & 25.9 & 110.4 & -0.18 & 5.5 & 124.4 & -1.1 & 5.8 & 16.0 \\
\hline KSK3 & 90.2 & -15.2 & 25.8 & 109.6 & -0.15 & 5.4 & 124.4 & -1.1 & 5.8 & 15.9 \\
\hline KSKW1 & 88.9 & -14.8 & 24.3 & 109.4 & -0.19 & 5.8 & 123.6 & -2.2 & 6.4 & 16.6 \\
\hline KSKW2 & 88.4 & -14.7 & 24.5 & - & - & - & 123.2 & -2.1 & 6.3 & 16.4 \\
\hline KSKW3 & 88.2 & -14.6 & 26.5 & - & - & - & 123.2 & -1.9 & 6.2 & 16.1 \\
\hline
\end{tabular}

some differences can be observed in case of peaks responsible for melting of crystalline structures of TPS and PEg-MA. It can be seen that these peaks are separating with each extrusion cycle, indicating achievement of different crystalline structure comparing to neat compounds. Such effect may be associated with the reaction occurring between maleic anhydride presented in grafted PE and hydroxyl groups present on the surface of TPS (general scheme of such reaction is presented above in the Fig. 1). Due to the polymorphism exhibited by PE-g-MA and the additional intermolecular interactions caused by this reaction, different crystal structures were formed [50]. According to literature data, multiple melting peaks are evidence of formation of various crystal structures, the duality of crystal configuration or reorganization of structure during DSC heating trace [51].
In Tables 6 and 7 there are summarized results of DSC analysis for all samples. Generally, two noticeable signals, both on heating and cooling curves were observed, which are associated with the melting and crystallization of semicrystalline polyethylene phase of EVA and PE-g-MA. The enthalpy of these transitions was used to calculate the part of PE crystalline phase in prepared samples according to the following formula (1):

$X_{c}=\frac{\Delta H_{m}}{\Delta H_{c}} \times 100 \%$

where $X_{c}$ is the degree of crystallinity, $\% ; \Delta H_{m}$ is the melting enthalpy, $\mathrm{J} / \mathrm{g} ; \Delta H_{c}$ is the melting enthalpy at $100 \%$ crystallinity, J/g. For calculations, heat of fusion of PE at $100 \%$

Table 7 Crystallization characteristics of used materials and TPS/EVA blends

\begin{tabular}{|c|c|c|c|c|c|c|c|c|c|}
\hline Sample & $\mathrm{T}_{\mathrm{cl}},{ }^{\circ} \mathrm{C}$ & $\Delta \mathrm{H}_{\mathrm{cl}}, \mathrm{J} / \mathrm{g}$ & $\mathrm{W}_{\mathrm{cl} 1 / 2-1},{ }^{\circ} \mathrm{C}$ & $\mathrm{T}_{\mathrm{c} 2},{ }^{\circ} \mathrm{C}$ & $\Delta \mathrm{H}_{\mathrm{c} 2}, \mathrm{~J} / \mathrm{g}$ & $\mathrm{W}_{\mathrm{c} 1 / 2-2},{ }^{\circ} \mathrm{C}$ & $\mathrm{T}_{\mathrm{c} 3},{ }^{\circ} \mathrm{C}$ & $\Delta \mathrm{H}_{\mathrm{c} 3}, \mathrm{~J} / \mathrm{g}$ & $\mathrm{W}_{\mathrm{c} 1 / 2-3},{ }^{\circ} \mathrm{C}$ \\
\hline TSZ & - & - & - & - & - & - & - & - & - \\
\hline TSK & - & - & - & - & - & - & - & - & - \\
\hline TSKW & - & - & - & - & - & - & - & - & - \\
\hline EVA & 71.4 & 56.9 & 5.0 & - & - & - & - & - & - \\
\hline PE-g-MA & - & - & - & - & - & - & 106.9 & 186.4 & 6.9 \\
\hline KSZ1 & 71.0 & 14.7 & 9.7 & 88.9 & 0.2 & 4.8 & 106.3 & 1.9 & 6.5 \\
\hline KSZ2 & 71.1 & 15.5 & 10.2 & - & - & - & 106.9 & 1.9 & 6.8 \\
\hline KSZ3 & 71.3 & 14.1 & 10.0 & - & - & - & 107.4 & 1.9 & 7.2 \\
\hline KSK1 & 70.1 & 13.4 & 10.2 & 88.1 & 0.3 & 5.0 & 105.2 & 1.8 & 7.4 \\
\hline KSK2 & 69.8 & 13.1 & 11.7 & - & - & - & 106.2 & 1.9 & 9.1 \\
\hline KSK3 & 70.1 & 13.3 & 11.4 & - & - & - & 106.6 & 2.0 & 9.0 \\
\hline KSKW1 & 71.6 & 16.5 & 11.1 & - & - & - & 108.6 & 2.6 & 8.1 \\
\hline KSKW2 & 71.6 & 17.0 & 11.3 & - & - & - & 108.6 & 2.3 & 8.2 \\
\hline KSKW3 & 71.6 & 17.6 & 11.6 & - & - & - & 108.7 & 2.3 & 8.4 \\
\hline
\end{tabular}



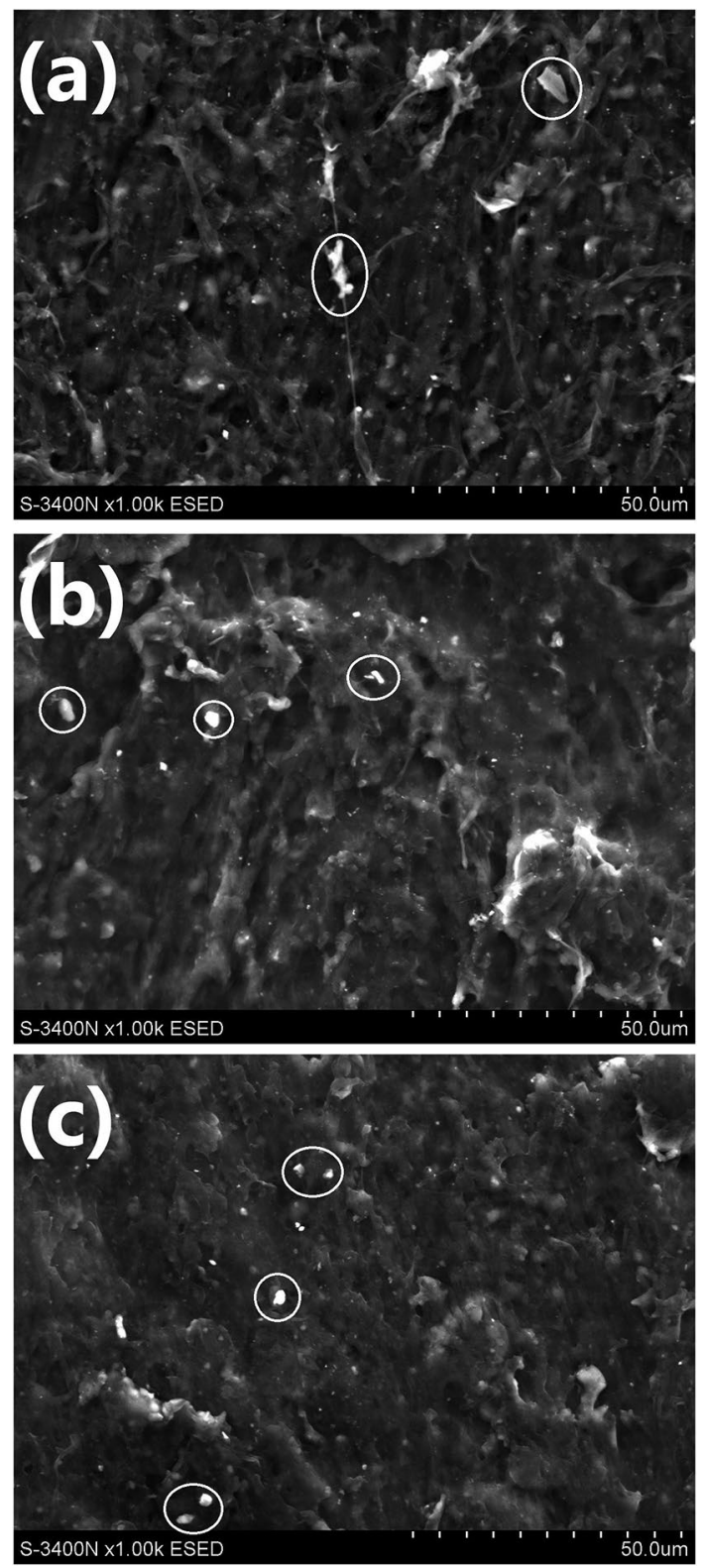

(2)

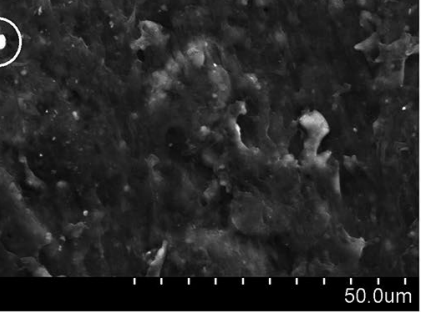

Fig. 12 Morphology of TPS/EVA blends based on waxy maize starch after $\mathbf{a}$ one, $\mathbf{b}$ two and $\mathbf{c}$ three extrusion cycles

crystallinity was assumed to be $293.6 \mathrm{~J} / \mathrm{g}$, according to literature data [52].

It can be seen that the crystallinity of EVA was slightly increased after preparation of composites, which was expressed by the values of $\Delta \mathrm{H}_{\mathrm{m}}$ and shifting the $\mathrm{T}_{\mathrm{m}}$ peak position towards higher temperatures [53]. On the other hand, crystallinity of PE-g-MA was disrupted when mixed with other compounds, which can be associated with the reactions occurring between grafted maleic anhydride and hydroxyl groups present in the structure of thermoplastic starch [54]. The same effect was observed for the signals associated with processing-induced crystallinity of TPS,
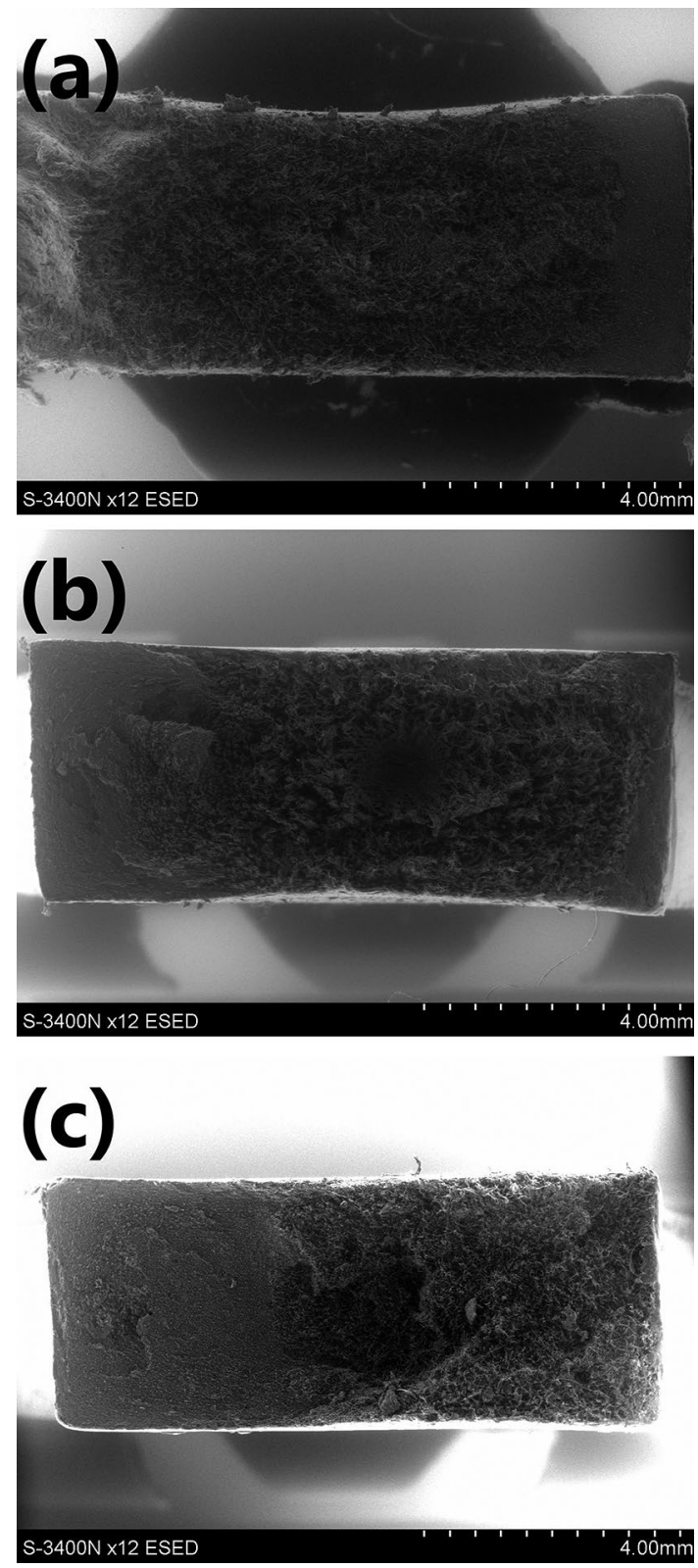

Fig. 13 SEM images of fracture surfaces of blends containing a potato starch, $\mathbf{b}$ maize starch and $\mathbf{c}$ waxy maize starch

which were even disappearing after multiple processing in case of KSKW samples.

Total degree of crystallinity of polyethylene phase in composites was slightly decreased by the multiple processing, which confirms the results presented in other research works [55].

In Tables 6 and 7 there are also presented values of peaks' width at half height, which represent the purity and homogeneity of crystalline phase structure, e.g. distribution of crystallites' size [56]. For EVA it can be seen that the half-width of peaks is noticeably higher in composite than in pure copolymer, while in case of PE-g-MA peaks, 


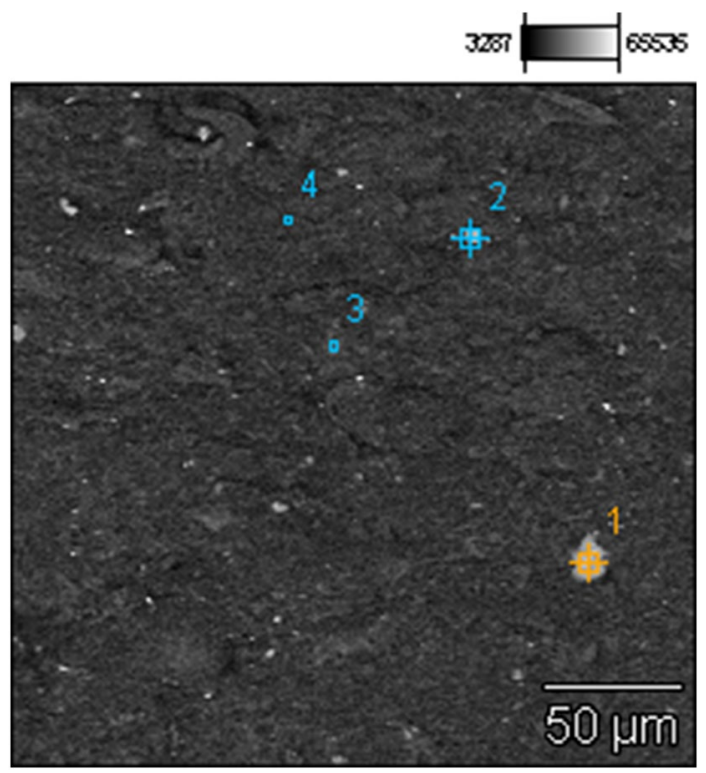

Fig. 14 SEM image of sample KSK1 with marked spots analyzed with EDS

half-width was almost unchanged, slightly lower for KSZ and KSK materials.

\section{Microscopic Analysis of TPS/EVA Blends}

In the Figs. 12 and 13 there are shown SEM images of prepared samples and their fracture surfaces after tensile tests. On the images of blends containing waxy maize starch (Fig. 12) it can be seen that the multiple extrusion cycles

(a)

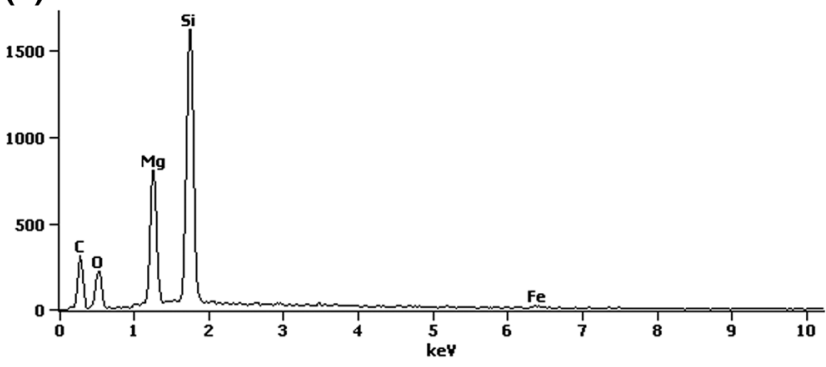

(c)

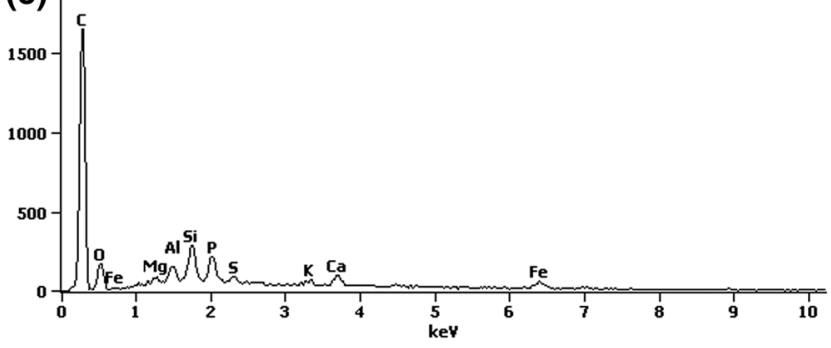

increased the homogeneity of materials. Similar effect was also observed for other types of starch. It can be associated with the longer residence time in extruder and additional mixing time, when high levels of shear are applied to the melt [57]. Similar effect associated with the morphological changes of PE/TPS blends, however after 5 and 10 extrusion cycles, was observed by Peres et al. [58]. Such noticeable effect after only two and three cycles is also related to the increasing extent of reaction occurring between maleic anhydride grafted to PE compatibilizer and hydroxyl groups present in the structure of starch (scheme presented in the Fig. 1). Effect of compatibilizer content on the sensitivity of polymer blends towards multiple processing cycles was evaluated for the polyamide/acrylonitrile-butadiene-styrene blends containing imidized acrylic polymers by Kudva et al. [59]. Authors stated that changes in morphology after multiple extrusions were noticeably more pronounced in the samples containing compatibilizer. Similar effect was observed for polyethylene/corn starch blends, when effectiveness of PE-g-GMA used as a compatibilizer was higher when reprocessed polyethylene was applied [60].

In the Fig. 13 there are shown images of TPS/EVA blends' fracture surfaces after tensile tests. It can be seen that the surface of materials depends on the type of TPS used. Samples containing starch with higher amylose content showed more ductile behavior. Such effect is related to the structure of amylose and amylopectin. Linear chains of amylose are able to slide on each other without disturbance caused by branching, occurring in case of amylopectin chains. As a result, high-amylopectin starches and their

(b)

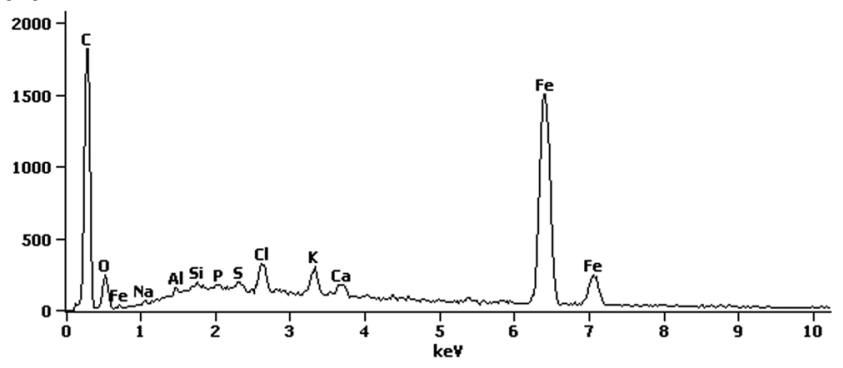

(d)

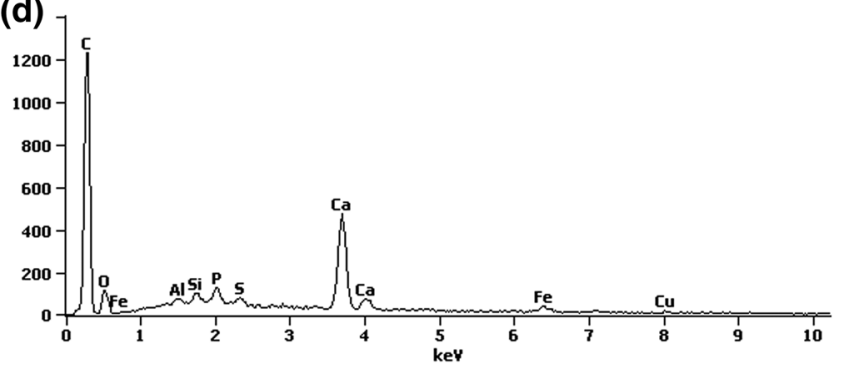

Fig. 15 Elemental composition of sample KSK1 (points of analysis marked in the Fig. 14) 
Table 8 Results of EDS analysis of KSK1 sample

\begin{tabular}{|c|c|c|c|c|c|c|c|c|c|c|c|}
\hline \multirow[t]{3}{*}{ Sample } & \multicolumn{11}{|c|}{ Element } \\
\hline & $\mathrm{Na}$ & $\mathrm{Mg}$ & $\mathrm{Al}$ & $\mathrm{Si}$ & $\mathrm{P}$ & $S$ & $\mathrm{Cl}$ & $\mathrm{K}$ & $\mathrm{Ca}$ & $\mathrm{Fe}$ & $\mathrm{Cu}$ \\
\hline & \multicolumn{11}{|c|}{ Content, wt $\%$} \\
\hline 1 & & 25.4 & & 70.2 & & & & & & 4.4 & \\
\hline 2 & 0.3 & & 0.4 & 0.4 & 0.3 & 0.6 & 2.5 & 2.5 & 1.4 & 91.6 & \\
\hline 3 & & 3.5 & 8.0 & 20.5 & 17.9 & 4.8 & & 4.3 & 11.0 & 30.1 & \\
\hline 4 & & & 1.8 & 3.6 & 5.7 & 3.6 & & & 65.9 & 14.4 & 4.9 \\
\hline \multirow[t]{3}{*}{ Sample } & \multicolumn{11}{|c|}{ Element } \\
\hline & $\mathrm{Na}$ & $\mathrm{Mg}$ & $\mathrm{Al}$ & $\mathrm{Si}$ & $\mathrm{P}$ & S & $\mathrm{Cl}$ & K & $\mathrm{Ca}$ & $\mathrm{Fe}$ & $\mathrm{Cu}$ \\
\hline & \multicolumn{11}{|c|}{ Content, $\%$} \\
\hline 1 & & 28.8 & & 69.0 & & & & & & 2.2 & \\
\hline 2 & 0.6 & & 0.7 & 0.8 & 0.5 & 1.0 & 3.8 & 3.5 & 1.8 & 87.3 & \\
\hline 3 & & 5.1 & 10.5 & 25.9 & 20.5 & 5.3 & & 3.9 & 9.7 & 19.1 & \\
\hline 4 & & & 2.7 & 5.2 & 7.5 & 4.5 & & & 66.5 & 10.4 & 3.1 \\
\hline
\end{tabular}

blends show brittle fracture and lower values of elongation at break, which have been already proven in literature [49, 61].

Moreover, in the Fig. 12, there are spots marked with white circles or ellipses. It can be seen that in that places can be observed solid particles, which are present due to the incorporation of sewage sludge during thermoplastification of starches. Such waste contains noticeable amounts of mineral substances containing elements such as phosphorous, potassium, magnesium, calcium, iron or silicon. Moreover, starch can also contain various impurities associated with its origin, contact with soil or fertilizers. For better characterization, EDS analysis was performed. This technique is valuable tool used to investigate polymeric materials containing various types of mineral fillers or impurities [62]. Its results were similar for all analyzed samples and no dependance between starch type or multiple processing and particular elements content was observed. Therefore, exemplary results for sample KSK1 are presented. In the Fig. 14, on SEM image, there are marked 4 spots, which were analyzed with EDS. Spectra for this points are presented in the Fig. 15 and the results of analysis are summarized in Table 8.

It can be seen that in each point different elemental composition was noted, which show very complex composition of applied sewage sludge. Obviously, high content of carbon and oxygen, seen in the Fig. 15, but not mentioned in Table 8 is associated with the presence of TPS, EVA copolymer and PE-g-MA applied as compatibilizer. Presence of other noted elements is typical for sewage sludge and was also noted by other researchers $[63,64]$. Moreover, presence of macro- and microelements in analyzed TPS/EVA blends can be considered beneficial from the ecological point of view. According to literature data, it could enhance activity of enzymes and microorganisms during potential biodegradation of such materials, which could create possible method of their recycling [65]. This phenomenon should be evaluated in further studies on this field.

\section{Conclusions}

Three types of starch: potato, maize and waxy maize, were subjected to thermoplastification process with glycerol and sewage sludge used as plasticizers. The influence of starch type and composition on the structure and properties of resulting thermoplastic starches was determined. In native starches, higher amylopectin content was associated with the change in type of crystallinity from B to A-type, which is associated with higher packing of the structure and gelatinization temperature. For TPS samples, no crystallinity was observed, however $\mathrm{T}_{\mathrm{g}}$ of the material was increasing with amylopectin content.

Thermoplastic starches, obtained from different starch sources were used to prepare TPS/EVA blends compatibilized with PE-g-MA. They were analyzed in terms of their structure and performance. FTIR analysis indicated some differences related to the starch type and content of amylopectin, possessing $\alpha$-1,6-glycosidic bonds, responsible for branching of this polysaccharide. Tensile properties of analyzed blends were also associated with the composition of applied TPS. With increasing content of branched amylopectin, blends showed higher tensile strength, while the opposite trend was observed for elongation at break. Such effect was related to the restriction of polymer chains' mobility. Such assumption was confirmed by the SEM analysis of fracture areas, which indicated more ductile 
behavior of samples containing potato starch with the highest amylose content.

Moreover, the impact of multiple processing cycles on the structure and performance of prepared blends was determined. FTIR analysis showed that additional processing time related to multiple extrusion increased the extent of reaction between maleic anhydride and hydroxyl groups of starch, which resulted in the enhancement of signal responsible for vibrations of ether bonds. This reaction had also noticeable effect on mechanical performance of materials. As a result of compatibility increasing with each processing cycle, tensile strength and elastic modulus of TPS/EVA blends were also increasing. Such effect was also confirmed by SEM analysis, which indicated more homogenous structure of analyzed blends after additional processing time.

Application of sewage sludge as a plasticizer of native starches resulted in the increased content of various elements in resulting blends. Such phenomenon can be further used to enhance the activity of microorganisms, which could be used for biodegradation of investigated blends.

Acknowledgements This work was supported by the Statutory Work of Central Mining Institute No. 11111017-161.

Open Access This article is distributed under the terms of the Creative Commons Attribution 4.0 International License (http://creativeco mmons.org/licenses/by/4.0/), which permits unrestricted use, distribution, and reproduction in any medium, provided you give appropriate credit to the original author(s) and the source, provide a link to the Creative Commons license, and indicate if changes were made.

\section{References}

1. Mohammadi Nafchi A, Moradpour M, Saeidi M, Alias AK (2013) Starch-Stärke 65(1-2):61

2. Zuo Y, Gu J, Tan H, Zhang Y (2015) J Wuhan Univ TechnolMater Sci Ed 30(2):423

3. Khan B, Bilal Khan Niazi M, Samin G, Jahan Z (2016) J Food Process Eng 40(3):e12447

4. Zhang Y, Rempel C, Liu Q (2014) Crit Rev Food Sci 54(10):1353

5. Huneault MA, Li H (2007) Polymer 48(1):270

6. Carvalho AJ, Job A, Alves N, Curvelo AA, Gandini A (2003) Carbohyd Polym 53(1):95

7. Koh JJ, Zhang X, He C (2018) Int J Biol Macromol 109:99

8. Reis KC, Pereira J, Smith AC, Carvalho CWP, Wellner N, Yakimets I (2008) J Food Eng 89(4):361

9. Bin-Dahman OA, Jose J, Al-Harthi MA (2015) Starch-Stärke 67(11-12):1061

10. Tang X, Alavi S (2011) Carbohyd Polym 85(1):7

11. Maliger RB, Halley PJ (2014) In: Halley PJ, Averous L (eds) Starch polymers. Elsevier, Amsterdam, p 291

12. Patel V (2009) Adv Mat Res 67:185

13. Da Róz AL, Ferreira AM, Yamaji FM, Carvalho AJF (2012) Carbohyd Polym 90(1):34

14. Zobel HF (1998) Starch-Stärke 40(2):44

15. Hubackova J, Dvorackova M, Svoboda P, Mokrejs P, Kupec J, Pozarova I, Alexy P, Bugaj P, Machovsky M, Koutny M (2013) Polym Test 32(6): 1011
16. Vinhas GM, de Lima SM, Santos LA, de Andrade Lima MAG, de Almeida YMB (2007) Braz Arch Biol Technol 50(3):361

17. Perez MA, Rivas BL, Rodriguez-Llamazares S (2013) J Chil Chem Soc 58(1):1643

18. Sadrmohaghegh C, Scott G, Setudeh E (1985) Polym-Plast Technol 24(2-3):149

19. Farahnaky A, Saberi B, Majzoobi M (2013) J Texture Stud 44(3): 176

20. Korol J, Lenża J, Formela K (2015) Compos B 68:310

21. Korol J, Lenza J, Burchart-Korol D, Bajer K (2012) Przem Chem 91(11):2196

22. Formela K, Korol J, Cysewska M, Haponiuk JT (2013) Przem Chem 92(4):512

23. Young AH (1984) In: Whistler RL, BeMiller JN, Paschall EF (eds) Starch chemistry and technology. Academic Press, London, p 249

24. Santha N, Sudha KG, Vijaykumari KP, Nayar VU, Moorthy SN (1990) J Chem Sci 102:705

25. Kubo S, Kadla JF (2005) Biomacromol 6:2815

26. Capron I, Robert P, Colonna P, Brogly M, Planchot V (2007) Carbohyd Polym 68(2):249

27. Sevenou O, Hill SE, Farhat IA, Mitchell JR (2002) Int J Biol Macromol 31(3):79

28. Lourdin D, Putaux JL, Potocki-Véronèse G, Chevigny C, RollandSabaté A, Buléon A (2015) Crystalline structure in starch. In: Nakamura Y (ed) Starch. Springer, Tokyo, p 61

29. Kizil R, Irudayaraj J, Seetharaman K (2002) J Agric Food Chem 50:3912

30. Mojet BL, Ebbesen SD, Lefferts L (2010) Chem Soc Rev 39(12):4643

31. Castillo L, López O, López C, Zaritzky N, García MA, Barbosa S, Villar M (2013) Carbohyd Polym 95(2):664

32. Yu L, Christie G (2001) Carbohyd Polym 46:179

33. Tako M, Tamaki Y, Teruya T, Takeda Y (2014) Food Nutr Sci 5(3): 280

34. Singh N, Singh J, Kaur L, Singh Sodhi N, Singh Gill B (2003) Food Chem 81(2):219

35. Rudnik E, Matuschek G, Milanov N, Kettrup A (2006) J Therm Anal Calorim 85(2):267

36. Mali S, Grossmann MVE, García MA, Martino MN, Zaritzky NE (2006) J Food Eng 75(4):453

37. LeCorre D, Bras J, Dufresne A (2011) J Nanopart Res 13(12): 7193

38. Todica M, Nagy EM, Niculaescu C, Stan O, Cioica N, Pop C (2016) J Spectrosc 2016:9605312

39. Lopez-Rubio A, Flanagan BM, Gilbert EP, Gidley MJ (2008) Biopolymers 89(9):761

40. Gironès J, López JP, Mutjé P, Carvalho AJF, Curvelo AAS, Vilasec F (2012) Compos Sci Technol 72:858

41. Angellier H, Molina-Boisseau S, Dole P, Dufresne A (2006) Biomacromol 7(2):531

42. Balakrishnan P, Sreekala MS, Kunaver M, Huskić M, Thomas S (2017) Carbohyd Polym 169:176

43. Balakrishnan P, Gopi S, Sreekala MS, Thomas S (2017) StarchStärke 70(1-2):1700139

44. Sills DL, Gossett JM (2012) Biotechnol Bioeng 109:353

45. Qin Y, Liu C, Jiang S, Xiong L, Sun Q (2016) Ind Crop Prod 87:182

46. Morán J, Alvarez V, Petrucci R, Kenny J, Vazquez A (2006) J Appl Polym Sci 103(1):228

47. Shujun W, Jiugao Y, Jinglin Y (2005) Polym Degrad Stabil 87(3):395

48. Zullo R, Iannace S (2009) Carbohyd Polym 77(2):376

49. Lawton JW (1996) Carbohyd Polym 29(3):203

50. Zubova EA (2013) In: Palsule S (ed) Encyclopedia of polymers and composites. Springer Verlag, Berlin

51. Chung WT, Yeh WJ, Hong PD (2002) J Appl Polym Sci 83:2426 
52. Wunderlich B, Dole M (1957) J Polym Sci 24(106):201

53. Sabetzadeh M, Bagheri R, Masoomi M (2015) Carbohyd Polym 119:126

54. Abdul Wahab MK, Ismail H, Othman N (2012) Polym-Plast Technol 51(3):298

55. Itim B, Philip M (2015) Polym Degrad Stabil 117:84

56. Chiu MH, Prenner EJ (2011) J Pharm BioAllied Sci 3(1):39

57. Eguiazábal JI, Nazábal J (1990) Polym Eng Sci 30(9):527

58. Peres AM, Pires RR, Oréfice RL (2016) Carbohyd Polym 136:210

59. Kudva RA, Keskkula H, Paul DR (2000) Polymer 41(1):239

60. Pedroso AG, Rosa DS (2005) Polym Adv Technol 16(4):310

61. Zhang M, Thomas NL (2009) J Appl Polym Sci 116(2):688
62. Varaprasad K, Pariguana M, Raghavendra GM, Jayaramudu T, Sadiku ER (2017) Mater Sci Eng C 70:85

63. Sommers LE (1977) J Environ Qual 6(2):225

64. Zhang FS, Nriagu JO, Itoh H (2005) Water Res 39(2-3):389

65. Tomaszewska-Ciosk E, Golachowski A, Zdybel E (2013) Pol J Chem Technol 15:110

Publisher's Note Springer Nature remains neutral with regard to jurisdictional claims in published maps and institutional affiliations. 